\title{
The IAU Strategic Plan for 2020-2030: OAD
}

\author{
Ewine F. van Dishoeck ${ }^{1}$ and Debra Meloy Elmegreen ${ }^{2}$ \\ ${ }^{1}$ Leiden Observatory, \\ P.O. Box 9513, NL-2300 RA, Leiden, the Netherlands \\ email: ewine@strw.leidenuniv.nl \\ ${ }^{2}$ Dept. of Physics \& Astronomy, Vassar College, \\ Poughkeepsie, NY 12604 USA \\ email: elmegreen@vassar.edu
}

\begin{abstract}
The IAU Strategic Plan for 2020-2030 presents an overview of all of the activities of the IAU along with priorities, key goals, mandates, and specific actions. Here future plans and goals are outlined for the Office of Astronomy for Development (OAD).
\end{abstract}

Keywords. editorials, notices

\section{Introduction}

The first formal Strategic Plan of the International Astronomical Union for the decade 2010-2020, was focused on the then-new Office of Astronomy for Development (OAD), which uses astronomy to impact UN Sustainable Development Goals (SDGs). At the XXIXth General Assembly in Honolulu, Hawaii, USA in August 2015, the Executive Committee agreed to present for approval at the XXXth General Assembly in Vienna, Austria in August 2018 an extended plan for future activities of the OAD. At the 98th Executive Committee (EC) meeting in Mexico City in May 2016, a working group was appointed, including Ewine van Dishoeck, Debra Elmegreen, Piero Benvenuti, and Renée Kraan-Korteweg. The EC further decided that the new Strategic Plan for 2020-2030 should encompass all activities of the IAU. The working group received extensive input from its membership and the various Offices, in particular from Kevin Govender and his team on the OAD part.

The final Strategic Plan 2020-2030 was presented for adoption as Resolution A1 at this XXXth GA, where it was approved at the second Business Meeting. The revised mission of the IAU is to "promote and safeguard astronomy in all its aspects (including research, communication, education, and development) through international cooperation," where the additional parenthetical aspects make explicit that the IAU has branched out beyond its original purpose of fostering scientific communication and exchange of ideas among professional astronomers.

\section{OAD and other Offices of the IAU}

The 3 current offices of the IAU were formed within the last decade to carry out additional aspects of IAU activities beyond the advancement of astronomy. The OAD, hosted in Cape Town, South Africa, focuses on the use of astronomy for development by capitalizing on the field's scientific, technological and cultural links and its impacts on society. It interacts with the other Offices. The Office of Young Astronomers, hosted by the Norwegian Academy of Science and Letters, focuses on the training of young astronomers at University level, and organizes the International School for Young Astronomers (ISYA). The Office for Astronomy Outreach (OAO), hosted by the National 


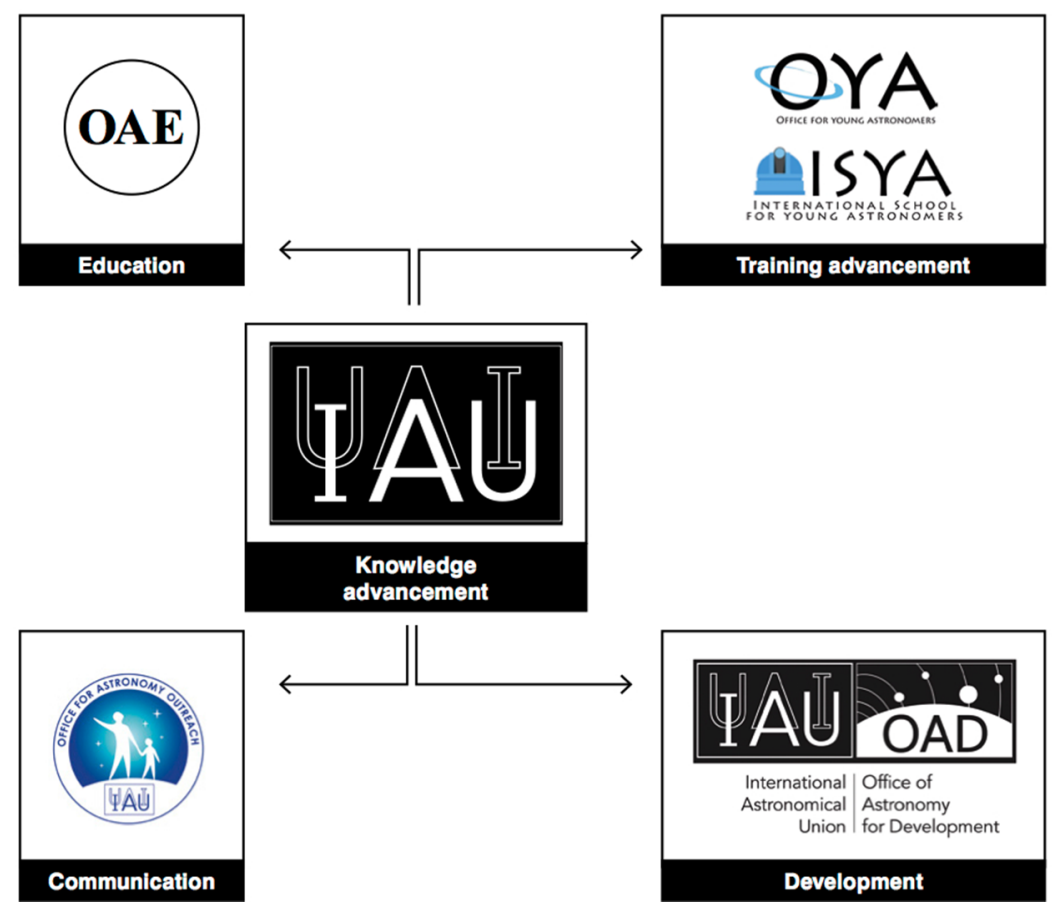

Figure 1. Interconnection of the Offices of the IAU.

Astronomical Observatory of Japan, focuses on engaging with the public, providing access to astronomical information and astronomy communication. It maintains a network of National Outreach Contacts (NOCs) and amateur groups. A new office is proposed: the Office of Astronomy for Education (OAE) will focus on providing training and resources for using astronomy as a stimulus for teaching and education from elementary to high school level (astronomy and science education). Each of these offices has its own strategic plan, and each office has a liaison on the EC to ensure that the strategic plans align with the overall goals of the IAU. Sometimes activities span more than one office, so having connections with the EC helps coordinate overlapping activities. Figure 1 is a schematic to emphasize the relations between the offices and the EC.

\section{Office of Astronomy for Development (OAD)}

The overarching goal of the OAD is to promote the use of astronomy as a tool for development in every country. More specifically, the OAD uses the UN Sustainable Development Goals (SDGs) as the global definition of development in calling annually for proposals. Fig. 2 below illustrates some potential contributions of astronomy to the SDGs. A goal for the 2020 - 2030 strategic plan is that - depending on the region - about half of the 232 SDG indicators should have been positively affected by OAD projects on all of the populated continents.

The Regional (ROADs) and Language (LOADs) Offices form the global core structure of the OAD and a goal is to further solidify and expand this network. Interactions between them stimulate synergies among different geographic and cultural regions. The OAD aims to identify a number of global 'signature' projects that can be expanded and regularly carried out worldwide in the next decade.

Partners from fields other than astronomy should also be included in this scheme, as astronomy connects with the space sector, ICT, branches of social sciences, relevant 


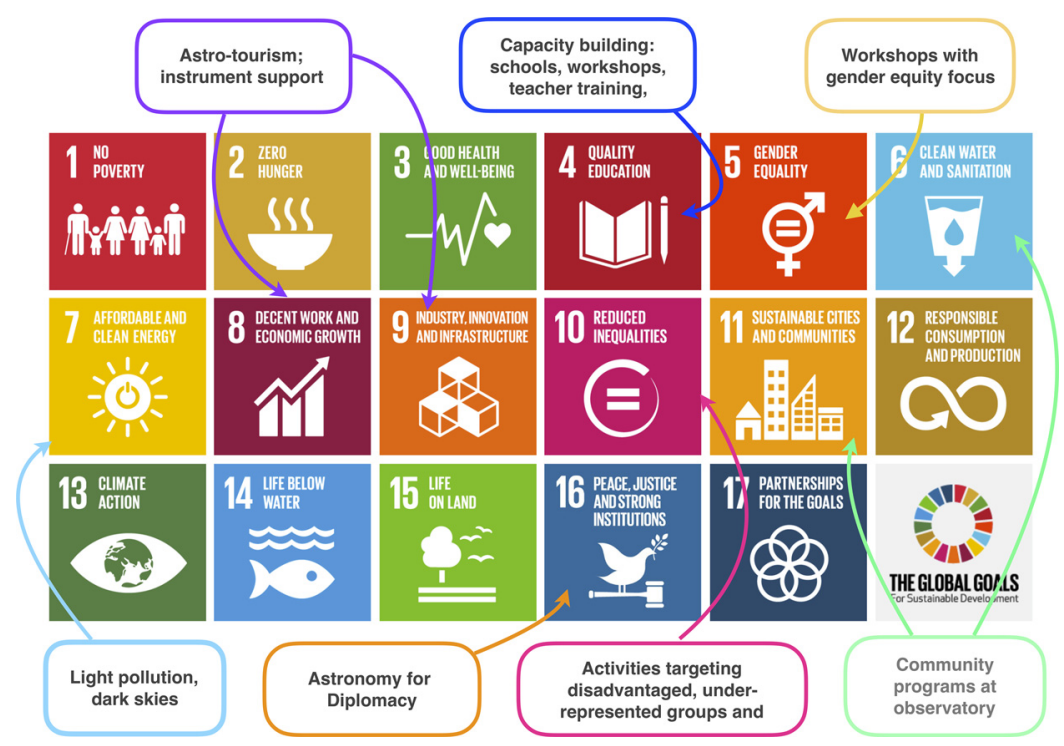

Figure 2. Potential contributions of astronomy to the SDGs.

industries and NGOs, art and cultural organisations. Indeed, an important goal of the $\mathrm{OAD}$ is to position young people for non-academic job opportunities in which they can apply the skills they have acquired in their career so far, as they are often in high demand. The field of astronomy can lead other sciences in terms of the societal benefits of blue skies research, and also with regard to the value that science brings to challenges facing humanity. The OAD can be a 'working space' for collaborations across sciences. The recent merger of the ICSU and ISSC clearly promotes such an approach.

\section{Conclusions}

We are grateful to the many people who have contributed to the achievements of the OAD in its first decade. Moving forward, the IAU depends on its members for the successful execution and implementation of the plan. Members are encouraged to continue to be involved in IAU activities through Working Groups, Commissions, Divisions, and Offices, and to encourage colleagues and early career astronomers to join the IAU and contribute to the OAD goals.

\section{References}

Astronomy for Development: Strategic Plan 2010-2020, https://www.iau.org/static/education/strategicplan_2010-2020.pdf IAU Strategic Plan 2020-2030, https://www.iau.org/static/education/strategicplan-2020-2030.pdf 